\title{
A Comparative Study of Cartesian and Delta 3D Printers on Producing PLA Parts
}

\author{
Betina Madeira Schmitt ${ }^{a}$, Christiano Fraga Zirbes ${ }^{a}$, Cassiano Bonin ${ }^{a}$, Daniel Lohmann ${ }^{b}$, Diovani \\ Castoldi Lencina ${ }^{a}$, Aurélio da Costa Sabino Netto ${ }^{*}$ * \\ ${ }^{a}$ Grupo de Pesquisa em Processos de Fabricação e Tecnologia dos Materiais - PFBMAT, Instituto \\ Federal de Santa Catarina, Av. Mauro Ramos, 950, 88020-300 - Florianópolis, SC, Brasil \\ ${ }^{b}$ Grupo de Automação Aplicada - GRA, Instituto Federal de Santa Catarina, Av. Mauro Ramos, 950, \\ 88020-300, Florianópolis, SC, Brasil
}

Received: December 20, 2016; Revised: December 20, 2017; Accepted: December 23, 2017

\begin{abstract}
The additive manufacturing processes emerged at the end of the last century and became popular by low-cost $3 \mathrm{D}$ printers. The most used printers work on a cartesian configuration, but recently were launched delta machines. These 3D printers use a more complex control system due to their trajectories generation but may present some advantages over the cartesian configuration. To increase the knowledge about additive manufacturing, a comparative study with cartesian and delta printers was performed to evaluate the performance on printing a testing part. Three samples were produced in each printer and compared based on surface quality, manufacturing time, mass and dimensional measurement. The printed objects were 3D scanned for comparing the digitized geometry by aligning the point cloud generated to its virtual 3D model. The parts produced in delta printer obtained better surface quality, while cartesian printer provided better dimensional accuracy. The results also showed that the variation of the mass and time to produce the parts were not significant.
\end{abstract}

Keywords: 3D printing, Cartesian Printer, Delta Printer, Dimensional Evaluation, Surface quality.

\section{Introduction}

The Fused Deposition Modeling (FDM) was originated in 1989 and patented in 1992 by the American company Stratasys ${ }^{1}$. Among the main additive manufacturing technologies available the most commercialized process worldwide is the $\mathrm{FDM}^{2}$.

The additive manufacturing processes are characterized by the same basic steps, differing in the way the layers are constructed $^{3}$. These processes were popularized by the creation of 3D printers, where objects are constructed layer-by-layer based on a virtual 3D model ${ }^{4}$.

In the FDM process, the layers are obtained from the deposition of a polymer through a hotend (extrusion head). The raw material is purchased on spools of filament of 1.75 or $3 \mathrm{~mm}$ diameter, which is directed to the inside of the hotend ${ }^{5}$. The hotend is endowed with heating components for plasticizing the filament. The pressure generated by the filament inlet promotes the extrusion of the molten material from the hotend through the nozzle.

Currently, the use of these technologies goes beyond its original purpose of rapid prototyping, allowing the production of final products ${ }^{6}$. The use of this technology advances in the most diverse areas of knowledge ${ }^{7}$. However, the applicability of the equipment has some limitation, especially considering the small production volume due to the size of the construction platform.

The most widely $3 \mathrm{D}$ printer configuration is the cartesian, meaning that the printing movements happen on the $\mathrm{X}, \mathrm{Y}$ and $\mathrm{Z}$ orthogonal axes. Core $\mathrm{XY}$ is one emerging configuration for cartesian printers that presents the extruder nozzle moves on the $\mathrm{X}$ and $\mathrm{Y}$ axes and the construction bed moves on the $\mathrm{Z}$ axis.

Recently were launched delta 3D printers that work differently than the cartesian ones. Once that delta printers are based on a parallel coordinate system ${ }^{8}$ they move by free trajectories generated through articulated axes, while the printing bed remains static (Figure 1 - adapted ${ }^{9}, 2014$ ).

Although delta printers move more complexly, they possibly present some advantages over cartesian ones, such as rapid speed and building capacity, higher production volume, less inertia of the extrusion assembly, less moving parts, easier enclosure and better temperature control ${ }^{8,10}$.

To investigate some of the differences between cartesian and delta printers, a comparative study was carried out through the construction of testing parts in $3 \mathrm{D}$ printers that work through the mentioned configuration systems. 


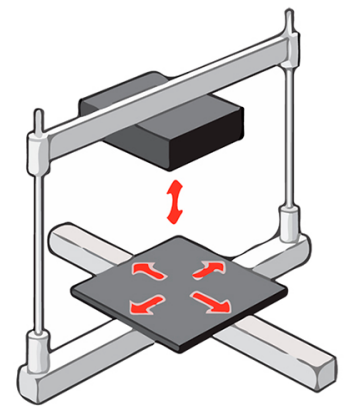

Cartesian

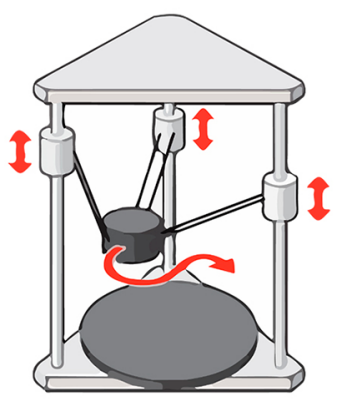

Delta
Figure 1. Schematic of cartesian and delta printers. Source: Earls e Baya (2014).

\section{Experimental Procedures}

\subsection{Testing geometry}

To compare the dimensional accuracy between the objects printed on the two types of printers, a testing part geometry was proposed. It presents a certain variety of measurements, inclining angles, different wall thicknesses and more than one shape - having a square base, a cylindrical top on the inside and an octagonal shape at the outer edge. After the geometry was settled, the segments to be measured were defined (Figure 2), as well as other aspects to the comparison, such as printing time and mass.
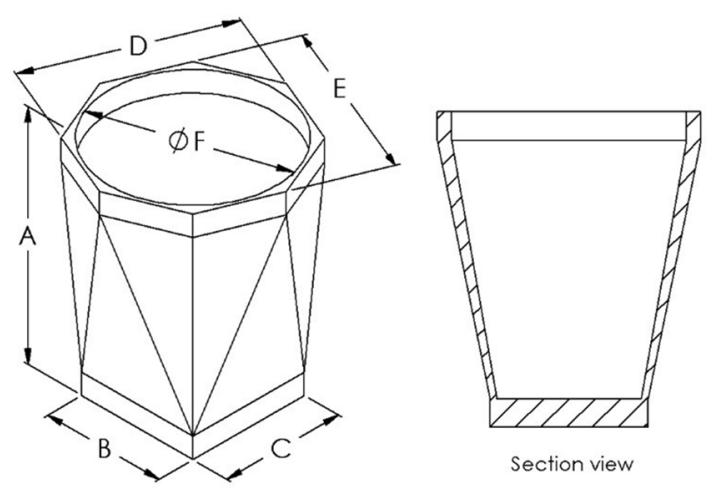

Figure 2. Evaluated dimensions on proposed geometry

\subsection{Printing procedures}

Three samples of the developed geometry were constructed in each printer used in this project: (1) the cartesian 3D Cloner DH printer (Figure 3), for which the GCode was generated in Slic3r software; and (2) the parallel coordinate system Rostock Max V2 (Figure 4), using the GCode generated by Matter Control software.

The material used to produce all parts was a gray PLA filament with a $1.75 \mathrm{~mm}$ diameter from ESUN supplier. The machines adopted extruder nozzles with $0.4 \mathrm{~mm}$ diameter and the same printing parameters $(60 \mathrm{~mm} / \mathrm{s}$ - printing speed,

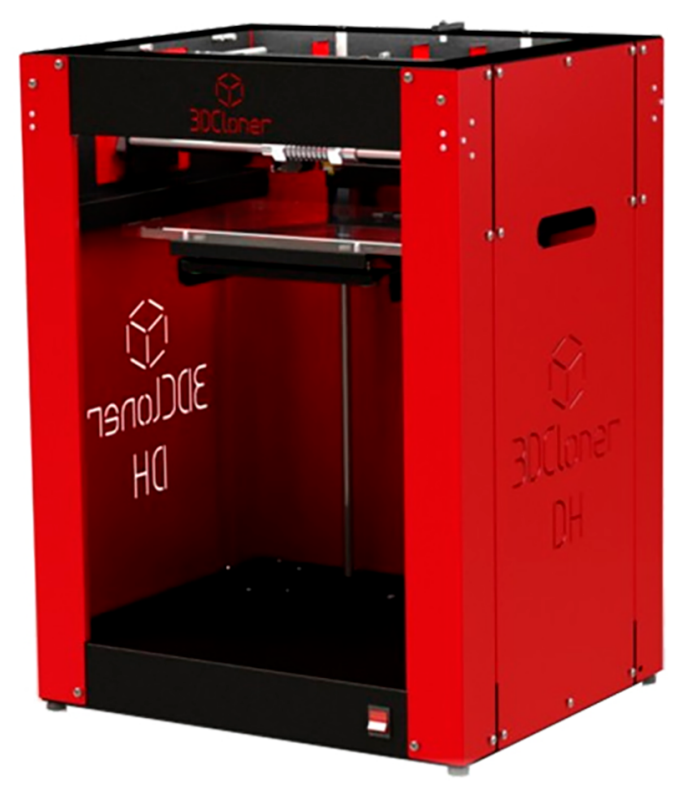

Figure 3. 3D Cloner DH Printer. Source: 3dcloner.com.br

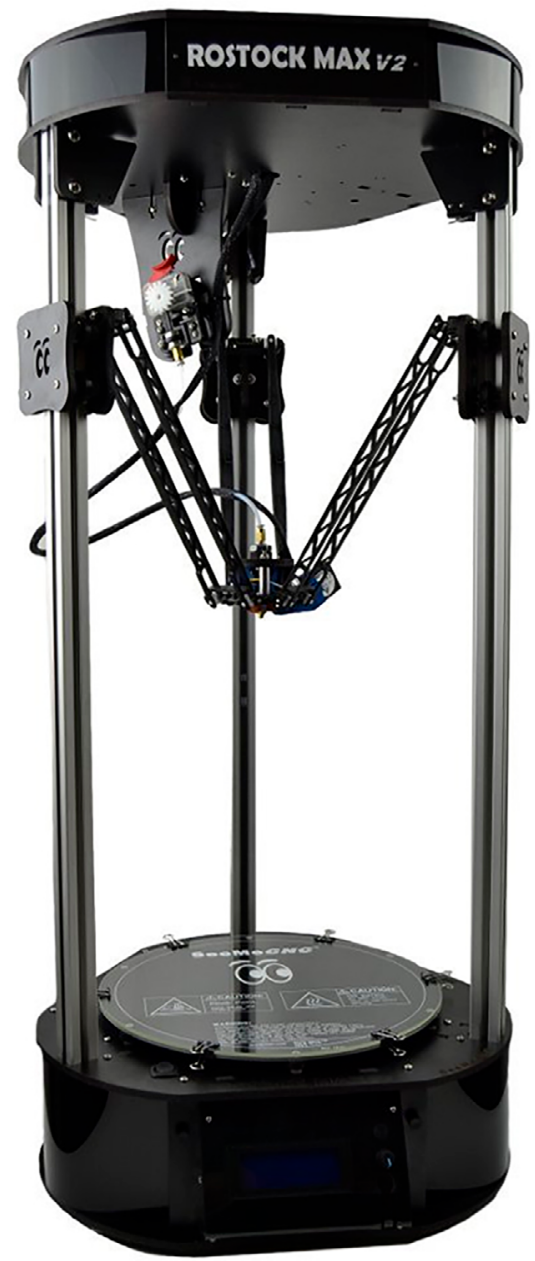

Figure 4. Rostock Max V2 Printer. Source: seemecnc.com 
$0.3 \mathrm{~mm}$ - layer thickness, $50 \%$ - infill density and $195^{\circ} \mathrm{C}$ - extrusion temperature). The bed temperature for Rostock was $60^{\circ} \mathrm{C}$ and for $3 \mathrm{D}$ Cloner was room temperature because this model does not have heated bed.

\subsection{Measuring procedures}

The dimensional evaluation was performed by using a RS2 LASER 3D scanner coupled to a 7-axis Romer Absolute Arm SI (Hexagon Metrology). This equipment captures a point cloud of the part, which was optimized by the PolyWorks Inspector software, allowing comparisons with the CAD model ${ }^{11}$. Three-dimensional scanners are widely used in dimensional object control. They are a versatile equipment, mainly in the measurement of complex geometry parts and its dimensional control tends to become faster than the coordinate measuring machines. The mass of the sample objects was measured on a digital scale with $0,01 \mathrm{~g}$ resolution.

\section{Results and Discussion}

\subsection{Printing quality}

To illustrate the printing quality, some specific details of the first geometry printed by Delta and Cartesian Printers were photographed (Figure 5). It is possible to observe that the part printed by the Rostock Max V2 had better finishing, presenting a smoother surface than the one printed by $3 \mathrm{D}$ Cloner.

In the images, it is also possible to verify that the transition between layers in the Rostock Max V2 printer is better than the one observed in the 3D Cloner. This may be related to the configuration of the slicing process parameters. When a layer is finished the machine moves only in $\mathrm{Z}$, during the time of movement, it is common for the hotend nozzle to continue to extrude the material, resulting in defects on the surface of the part.

Some defects observed in the parts produced by the 3D Cloner are related to excessive extrusion were observed. These defects can be also assigned to the adjustment of the process parameters and the firmware of the equipment.

\subsection{Mass, build time and dimensional evaluation}

The information of the mass, build time and dimensional data collected by analyzing the six printed parts were compared side by side to highlight the measurements, average and standard deviation (Table 1).

The average mass of the parts obtained by the two printers was very close. The $3 \mathrm{D}$ Cloner obtained a $5 \%$ higher average value, however it did not prove significant due to the large standard deviation in the manufactured parts.

The build time of the parts was considerably shorter in the Rostock Max V2 printer with an average time of

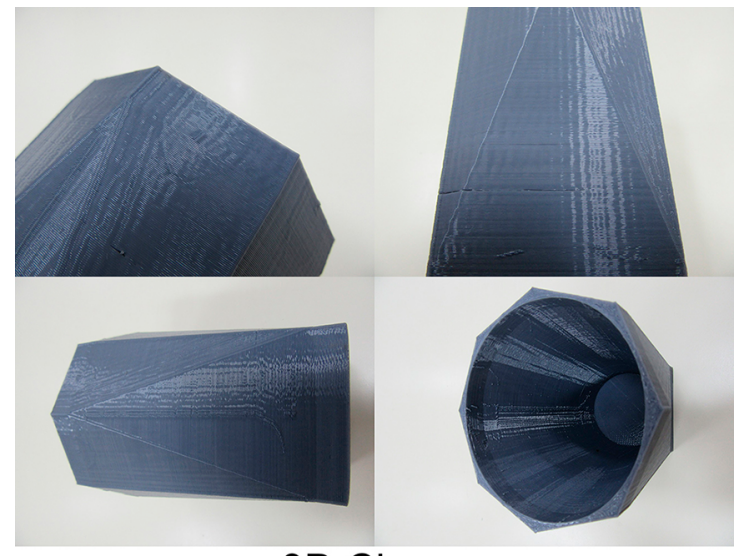

\section{D Cloner}

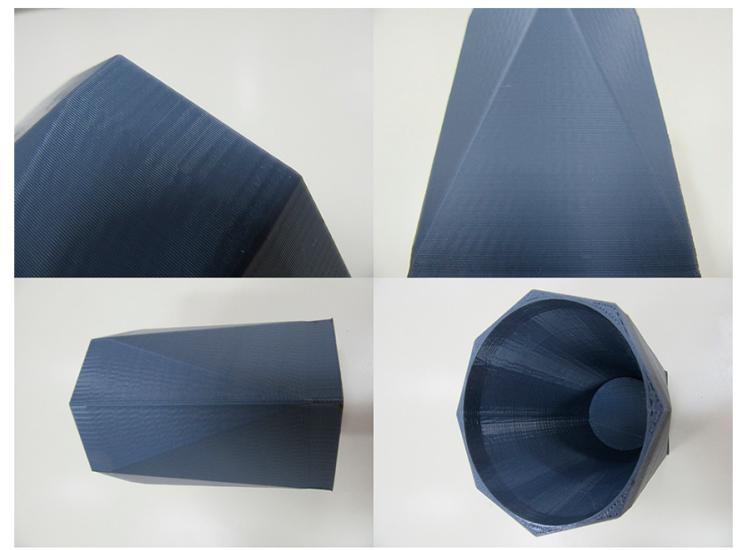

Rostock Max

Figure 5. Surface details on 3D printed parts

5h50min. The 3D Cloner printer showed a large dispersion over the manufacturing times. This variation may be related to communications problems between printer and computer that controls it.

On the dimensions evaluated in comparison between printers the $3 \mathrm{D}$ Cloner showed better accuracy $(0.5 \%$ on average). The Rostock Max V2 printer built parts around 1.1\% larger than the CAD model but presented less dispersion in the measurements which was three times smaller on average. It should be noted that unlike the 3D Cloner printer, sold fully assembled, the Rostock Max V2 used was assembled from a DIY kit. Subsequent settings for printer calibration can improve the accuracy of the printer.

The point cloud obtained through LASER scanning of the parts was overlapped with the virtual 3D model to provide an overview of dimensional accuracy of the printed objects. In Figure 6 the deviations are presented through color scales representing positive and negative values. Through the color gradient it is possible to identify that the part obtained in the delta printer was relatively larger than the CAD model on external surface confirming the results of previous measurements. 
Table 1. Results of build time, dimensional and mass measurements of printed objects.

\begin{tabular}{|c|c|c|c|c|c|c|c|c|c|c|c|}
\hline \multirow{2}{*}{\multicolumn{2}{|c|}{$\begin{array}{l}\text { CAD } \\
\text { Model }\end{array}$}} & \multicolumn{5}{|c|}{ 3D Cloner } & \multicolumn{5}{|c|}{ Rostock Max V2 } \\
\hline & & \multirow{2}{*}{$\begin{array}{c}\# 1 \\
110.42\end{array}$} & \multirow{2}{*}{$\begin{array}{c}\# 2 \\
110.63\end{array}$} & \multirow{2}{*}{$\frac{\# 3}{110.48}$} & \multirow{2}{*}{$\frac{\bar{x}}{110.51}$} & \multirow{2}{*}{$\begin{array}{c}\mathrm{s} \\
0.11\end{array}$} & \multirow{2}{*}{$\begin{array}{c}\# 1 \\
110.10\end{array}$} & \multirow{2}{*}{$\begin{array}{c}\# 2 \\
110.01\end{array}$} & \multirow{2}{*}{$\begin{array}{c}\text { \#3 } \\
109.99\end{array}$} & \multirow{2}{*}{$\frac{\bar{x}}{110.03}$} & \multirow{2}{*}{$\frac{\mathrm{s}}{0.06}$} \\
\hline $\mathrm{A}(\mathrm{mm})$ & 110 & & & & & & & & & & \\
\hline B (mm) & 55 & 54.96 & 55.04 & 55.34 & 55.11 & 0.20 & 55.87 & 56.10 & 56.04 & 56.00 & 0.12 \\
\hline $\mathrm{C}(\mathrm{mm})$ & 55 & 54.93 & 55.10 & 55.27 & 55.10 & 0.17 & 55.55 & 55.75 & 55.71 & 55.67 & 0.11 \\
\hline $\mathrm{D}(\mathrm{mm})$ & 85 & 83.52 & 84.96 & 84.86 & 84.45 & 0.80 & 85.90 & 86.40 & 86.23 & 86.18 & 0.25 \\
\hline $\mathrm{E}(\mathrm{mm})$ & 85 & 84.78 & 85.20 & 85.59 & 85.19 & 0.41 & 86.18 & 86.14 & 86.41 & 86.24 & 0.15 \\
\hline $\mathrm{F}(\mathrm{mm})$ & 82 & 81.69 & 79.99 & 81.47 & 81.05 & 0.92 & 82.66 & 82.31 & 82.61 & 82.53 & 0.19 \\
\hline \multicolumn{2}{|c|}{ Build time (h:min) } & $05: 40$ & $07: 54$ & $12: 00$ & $08: 31$ & $03: 12$ & $06: 12$ & $05: 33$ & $05: 46$ & $05: 50$ & $00: 19$ \\
\hline \multicolumn{2}{|c|}{ Mass (g) } & 117.00 & 132.76 & 133.33 & 127.70 & 9.27 & 114.28 & 125.87 & 124.21 & 121.45 & 6.27 \\
\hline
\end{tabular}
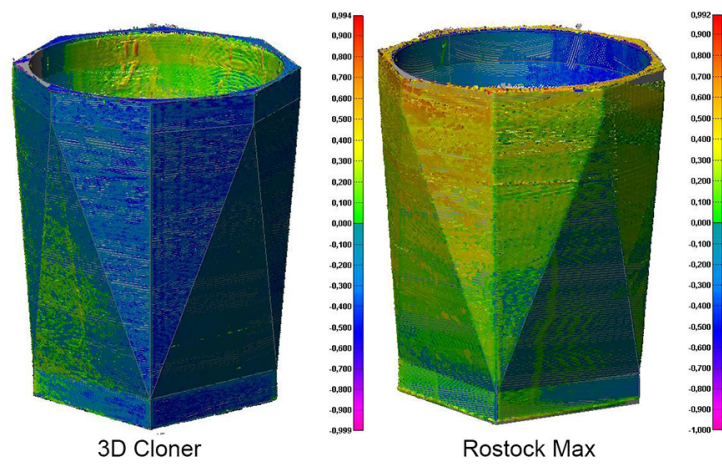

Figure 6. Comparative of $\mathrm{CAD}$ model and $3 \mathrm{D}$ printed parts

\section{Conclusions}

Based on the comparative study, it is possible to affirm that the Rostock Max V2 printer gives a better surface finish. Regarding the building time, the 3D Cloner performed the construction about $10 \%$ faster when comparing the first part in each printer. However, it presented an unusual behavior when printing the third part, taking 12 hours to complete the printing and manufacturing a worse surface finish than the previous ones.

The mass variation between the parts was around 5\% and the dimensional evaluation revealed that the $3 \mathrm{D}$ Cloner printer presented a better accuracy when compared to the CAD model. The worse dimensional accuracy observed in Rostock Max V2 printings may be related to its calibration, but only further studies could validate this hypothesis.

The parts printed on both printers show similar results, but the best performance of the delta printer was evident in terms of finishing quality. It can be concluded that the printing result obtained depends on how much the process parameters and the firmware of each machine are suitable for the parts to be printed.

\section{Acknowledgments}

The authors are grateful to Instituto Federal de Santa Catarina (IFSC) for the financial support.

\section{References}

1. Crump SS, inventor; Stratasys Inc, assignee. Apparatus and method for creating three-dimensional objects. United States patent US 5121329. 1992 Jun 09.

2. Wohlers Associates. Wohlers Report 2015. 3D Printing and Additive Manufacturing State of the Industry Annual Worldwide Progress Report. Fort Collins: Wohlers Associates; 2015.

3. Souza AF, Ulbrich CB. Engenharia Integrada por Computador e Sistemas CAD / CAM / CNC - Principios e Aplicações. São Paulo: Artliber Editora; 2009.

4. Sauramo H. The proliferation of a new-market disruptive innovation: case personal 3D printers [Internet]. [Master's Degree]. Aalto: Aalto University School of Business, Department of Management Studies; 2014. Available from: <http://epub.lib. aalto.fi/en/ethesis/pdf/13730/hse ethesis_13730.pdf $>$. Access in: $02 / 08 / 2016$.

5. Volpato N, ed. Prototipagem Rápida: Tecnologias e Aplicações. São Paulo: Edgard Blücher; 2007.

6. Gao W, Zhang Y, Ramanujan D, Ramani K, Chen Y, Williams CB, et al. The status, challenges, and future of additive manufacturing in engineering. Computer-Aided Design. 2015;69:65-89.

7. Barnatt C. 3 D Printing. $2^{\text {nd }}$ ed. [Internet]; 2014. Available from: explainingthefuture.com. Access in: 10/09/2016.

8. Tomei GPS. Desenvolvimento de um protótipo de um robô de cinemática paralela do tipo delta para impressão tridimensional de peças. [Completion of course work]. Lajeado: UNIVATES;2014.88 p.

9. Curran C. The road ahead for 3-D printing [Internet]. 2014. Available from: <http://www.pwc.com/us/en/technologyforecast/2014/3d-printing/features/future-3d-printing.html $>$. Access in: 20/11/2016.

10. Bell C. 3D Printing with Delta Printers. New York: APRESS; 2015. $268 \mathrm{p}$.

11. Innovmetric. Polyworks. The Universal 3D Metrology Software Platform [Internet]; 2015. Available from: <http://www. innovmetric.com>. Access in: 11/11/2015. 